\title{
Discriminative detection and enumeration of microbial life in marine subsurface sediments
}

\author{
Yuki Morono ${ }^{1}$, Takeshi Terada ${ }^{2}$, Noriaki Masui ${ }^{1}$ and Fumio Inagaki ${ }^{1}$ \\ ${ }^{1}$ Geomicrobiology Group, Kochi Institute for Core Sample Research, Japan Agency for Marine-Earth Science \\ and Technology (JAMSTEC), Nankoku, Kochi, Japan and ${ }^{2}$ Marine Works Japan Co., Kamariyahigashi, \\ Yokohama, Japan
}

\begin{abstract}
Detection and enumeration of microbial life in natural environments provide fundamental information about the extent of the biosphere on Earth. However, it has long been difficult to evaluate the abundance of microbial cells in sedimentary habitats because non-specific binding of fluorescent dye and/or auto-fluorescence from sediment particles strongly hampers the recognition of cell-derived signals. Here, we show a highly efficient and discriminative detection and enumeration technique for microbial cells in sediments using hydrofluoric acid (HF) treatment and automated fluorescent image analysis. Washing of sediment slurries with HF significantly reduced non-biological fluorescent signals such as amorphous silica and enhanced the efficiency of cell detachment from the particles. We found that cell-derived SYBR Green I signals can be distinguished from non-biological backgrounds by dividing green fluorescence (band-pass filter: $528 / 38 \mathrm{~nm}$ (center-wavelength/bandwidth)) by red $(617 / 73 \mathrm{~nm})$ per image. A newly developed automated microscope system could take a wide range of high-resolution image in a short time, and subsequently enumerate the accurate number of cell-derived signals by the calculation of green to red fluorescence signals per image. Using our technique, we evaluated the microbial population in deep marine sediments offshore Peru and Japan down to $365 \mathrm{~m}$ below the seafloor, which provided objective digital images as evidence for the quantification of the prevailing microbial life. Our method is hence useful to explore the extent of sub-seafloor life in the future scientific drilling, and moreover widely applicable in the study of microbial ecology.
\end{abstract}

The ISME Journal (2009) 3, 503-511; doi:10.1038/ismej.2009.1; published online 12 February 2009

Subject Category: microbial population and community ecology

Keywords: sub-seafloor biosphere; life detection; microbial population; image analysis

\section{Introduction}

Detection of microbial cells and their enumeration are initial steps towards a better understanding of microbial ecosystems and the extent of the Earth's biosphere. Fluorescent dyes such as 4',6-diamidino2-phenylindole (DAPI: Poter and Feig, 1980), acridine orange (AO; Daley and Hobbie, 1975), SYBR Green I (SYBR-I: Noble and Fuhrman, 1998, Patel et al., 2007) and SYBR Green II (SYBR-II: Weinbauer et al., 1998) stain intracellular nucleic acid (DNA and/or RNA), which allows subsequent enumeration of cells by microscopic observation of the fluorescence. These approaches have been success-

Correspondence: F Inagaki, Geomicrobiology Group, Kochi Institute for Core Sample Research, Japan Agency for MarineEarth Science and Technology (JAMSTEC), Monobe B200, Nankoku, Kochi, Japan.

E-mail: inagaki@jamstec.go.jp

Received 20 October 2008; revised 8 December 2008; accepted 16 December 2008; published online 12 February 2009 fully implemented in aquatic environments; however, studies of geological samples (that is, soil, sediment and rock) have long been hampered by high background and non-specific fluorescence signals, and hence methodological improvements have long been in high demand.

The marine subsurface environment is considered as the largest biosphere that harbors one-tenth of the living biota on Earth (Parkes et al., 1994, 2000; Whitman et al., 1998; Lipp et al., 2008). It comprises diverse microbial populations (for example, Inagaki et al., 2003, 2006; Teske 2006; Inagaki and Nakagawa, 2008). In deep marine sediments, the discrimination of microbial life is significantly more difficult than in surface sediments and terrestrial soils because cell abundances are generally decreasing with increasing the sediment depth (Parkes et al., 1994, 2000) and the buried cells have extremely low metabolic activities (D'Hondt et al., 2002, 2004). Moreover, a highly consolidated sediment matrix produces auto-fluorescence from diatomaceous 
spicules and other mineral particles. The cell abundance in marine subsurface sediments has conventionally been evaluated by AO direct count (AODC: Cragg et al., 1995; Parkes et al., 2000) down to $1613 \mathrm{~m}$ below the seafloor (mbsf: Roussel et al., 2008). As the cell-derived AO signals often fade out in a short exposure time, recognizing and counting of cells require specialized training. Hence, such efforts to enumerate AO-stained cells from the subseafloor on photo-images have been difficult and verification of findings by others has been impossible. In addition, to provide mean statistical values from low biomass sedimentary habitats has been complicated by human efforts and time limitations, yet these habitats are considered critical for understanding the Earth's biosphere close to the limits of habitable zones (Hoehler 2004; D'Hondt et al., 2007).

Recently, SYBR-I or SYBR-II is considered a more effective fluorescent dye for cell enumeration in sediments than AO due to its higher fluorescent intensity and sensitivity to nucleic acids (Weinbauer et al., 1998; Lunau et al., 2005; Engelen et al., 2008). However, by using the filter set for excitation and detection of the SYBR green fluorescence, many particles emitting bright auto-fluorescence have been still found in microscopic fields, which are extremely difficult to distinguish from cell-derived SYBR fluorescent signals. Thus, although SYBR staining produces intense fluorescence on binding to cellular nucleic acids, co-existing non-biological backgrounds are supposed to result in serious overestimation of cell abundance.

In this study, we carried out an image analysis to discriminate cell-derived SYBR-I fluorescent signals from problematic backgrounds in marine subsurface sediment samples. To increase cell-detachment efficiency and reduce non-specific background signals from sediment particles, we treated sediment samples with hydrofluoric acid (HF). In addition, the automated microscope system was developed for rapid and wide-range scanning of the filter image. Our method present here resulted in accurate and objective enumeration of microbial cells in very difficult setting: the deep marine subsurface. Hence, the technique is widely applicable to the study of microbial ecology.

\section{Materials and methods}

Sediment core sampling

Core samples of marine subsurface sediments were collected by the Ocean Drilling Program (ODP) Leg 201 offshore Peru (Sites 1227 and 1230) and the eastern equatorial Pacific (Site 1226) in 2002 (D'Hondt et al., 2004), by the Chikyu Shakedown Expedition CK06-06 offshore the northeastern Japan (Site C9001) in 2006 (Masui et al., 2008; Kobayashi et al., 2008), and by the Integrated Ocean Drilling Program (IODP) Expedition 316 (Site C0006) from the Nankai Trough in 2008. The core samples of ODP Leg 201 were stored at $-20^{\circ} \mathrm{C} .1-\mathrm{cm}^{3}$ regions of the innermost frozen ODP cores were obtained in a laminar-flow clean cabinet and then the slurry was immersed in $2 \%(\mathrm{w} / \mathrm{v})$ paraformaldehyde in PBS buffer ( $\mathrm{pH}$ 7.6). After the frozen sediment melts in the paraformaldehyde solution, the slurry was vortexed for $10 \mathrm{~s}$, and then incubated at $4{ }^{\circ} \mathrm{C}$ for $6 \mathrm{~h}$. The samples from Sites C9001 and C0006 were freshly taken onboard and fixed immediately as described above. The fixed slurry samples were washed twice with PBS buffer, resuspended in $10 \mathrm{ml}$ of PBS-ethanol (1:1) solution, and stored at $-20^{\circ} \mathrm{C}$ before laboratory use. Cultured E. coli cells were fixed as described above. To prepare cell-free sediment sample as a control, hemi-pelagic diatom-rich clay sediment (Core 2T-3 of CK06-06) was heat sterilized at $450{ }^{\circ} \mathrm{C}$ for $3 \mathrm{~h}$ and then suspended in PBS buffer $(10 \%(\mathrm{v} / \mathrm{v}))$.

\section{Filter preparation}

Cell abundance in core sediments was assessed by microscopic counts of SYBR Green I (Molecular Probes-Invitrogen, Carlsbad, CA, USA)-stained cells. Fifty microliters of slurry $(10 \%(\mathrm{v} / \mathrm{v})$ sediment in ethanol-PBS solution) fixed in $2 \%$ paraformaldehyde was mixed with $450 \mu \mathrm{l}$ of $\mathrm{HF}$ solution $(1.0 \%$ (wt/v) $\mathrm{HF}, 3 \%(\mathrm{wt} / \mathrm{v}) \mathrm{NaCl})$ in a plastic test tube and then incubated for $20 \mathrm{~min}$ at room temperature. The HF reaction was stopped by adding $2 \mathrm{ml}$ of stop solution (1 M Tris-hydrochloric acid (HCl) ( $\mathrm{pH} 8.0$ ), $0.125 \mathrm{M}$ $\mathrm{CaCl}_{2}$ and $25 \%$ methanol). The dilution factor for the original sample was 1:500 at this step. The mixture was sonicated at $20 \mathrm{~W}$ for $1 \mathrm{~min}$ on ice using an ultrasonic homogenizer (Model UH-50, SMT Co. Ltd., Tokyo, Japan), and then $50-750 \mu \mathrm{l}$ of the sonicate was mixed with $2.5 \mathrm{ml}$ of $3 \% \mathrm{NaCl}$, and directly filtered through a $0.22-\mu \mathrm{m}$-pore size black polycarbonate membrane without centrifugation. Thus, the final sediment volumes on the filter correspond to the range of $1.0 \times 10^{-4}-1.5 \times 10^{-3} \mathrm{~cm}^{3}$. To eliminate potential carbonate particles and/or precipitates, the membrane was treated with $1 \mathrm{ml}$ of $0.1 \mathrm{M} \mathrm{HCl}$ for $5 \mathrm{~min}$ on the filtration device. The membrane was then washed with $5 \mathrm{ml}$ of TE buffer ( $10 \mathrm{mM}$ Tris-HCl, 1.0 mM EDTA, pH 8.0) and air-dried. A quarter of the membrane was cut, placed on a glass microscope slide, and then mounted with $3 \mu$ l SYBR-I staining solution $(1 / 40(\mathrm{v} / \mathrm{v})$ SYBR-I and $0.1 \% p$-phenylenediamine in a 1:2 mixture of VECTASHIELD mounting medium H-1000 (Vector Lab. Ltd., Peterborough, UK) and TE buffer).

\section{Acridine orange staining}

After adding stop solution to the acid-washed slurry, one quarter of the same membrane that was used for SYBR-I stain was placed on the filtration device with a cellulose acetate backing filter. One milliliter of $0.1 \%(\mathrm{w} / \mathrm{v})$ AO that had been filtered in advance 
through a $0.22-\mu \mathrm{m}$-pore membrane, was placed on the filter and incubated for $5 \mathrm{~min}$ at room temperature. After vacuum filtration, the membrane was washed with $0.1 \mathrm{M}$ sodium citrate buffer ( $\mathrm{pH} 4.0$ ), air-dried, transferred to a glass microscope slide, and then mounted with $2 \mu \mathrm{l}$ of mounting solution $(0.1 \% p$-phenylenediamine in a $1: 2$ mixture of VECTASHIELD mounting medium $\mathrm{H}-1000$ and TE buffer).

\section{Automated fluorescent microscope system}

All 140 ( $\times 100$ objective lens) or 285 ( $\times 40$ objective lens) images per sample were automatically acquired with an epifluorescent microscope (BX-51, Olympus, Tokyo, Japan) equipped with a cooled CCD camera (ORCA-AG, Hamamatsu photonics K.K., Osaka, Japan) under the control of MetaMorph software, version 7.5 (Molecular Devices, Downingtown, PA, USA). A band-pass filter of $490 / 20 \mathrm{~nm}$ (center wavelength/bandwidth) was used for excitation, and 528/38 nm (green) and 617/73 nm (red) filters were used for the detection of cell-derived SYBR-I signals and non-cellular background fluorescence, respectively. The fluorescence spectra of cell-derived and non-specific SYBR-I signals were measured by a multi-spectral imaging system (Nuance GN-500, Kurabo Industries Ltd, Osaka, Japan) under the same excitation wavelength. The 'Scan Slide' function of the MetaMorph software controlled the scanning, whereas automatically adjusting the focus on each image. The basic algorithm for the focus adjustment is based on the breadth of the intensity histogram throughout the entire image. Thus, the focus adjustment frequently failed for the images with approximately $<10$ fluorescent signals (data not shown) because the small area of high intensity compared with the entire image was less significant on the intensity histogram. To establish fine focus throughout the images regardless of the number of microbial cells per image, we added microsphere beads (Fluoresbrite Bright Blue Carboxylate Microspheres (BB beads), $0.5 \mu \mathrm{m}$, Polysciences, Inc. Warrington, PA, USA) that fluoresce only under the UV filter set (excitation, 350/50 nm; emission, 457/60 nm). We then modified the sequence of the automated microscope system as follows: (i) scan z-position under the UV filter set to focus on BB beads, (ii) fix z-mortar and acquire bead image, (iii) change filter set to green, (iv) acquire cell image, (v) change filter set to red and (vi) acquire background image. The exposure times were $800 \mathrm{~ms}$ for both SYBR-I-stained cells and non-cellular background and $20 \mathrm{~ms}$ for the BB beads.

\section{Fluorescent image analysis}

The fluorescence intensity of each pixel in the green image was automatically multiplied by 100 and divided by that of the red image at the same location.
Resulting images showing the ratio (\%) of the relative intensity of green/red fluorescence were smoothed by the median filter $(3 \times 3$ pixel square), and watershed lines were drawn to separate cells in close proximity to each other. Based on the E. coli images in control sediments and cellular signals in natural sub-seafloor sediments, we set the threshold value of relative fluorescence at 110 for automatic cell enumeration. Under these threshold conditions, non-specific signals in heat-sterilized sediments, as well as on blank filters resulted in a null count. For computer counting without image analysis, all images were smoothed using a median filter $(3 \times 3$ pixel square), and then fluorescent signals were counted with the 'Count Nuclei' function of the MetaMorph software. This function detects fluorescent signals higher than those of the surrounding background. The size discrimination was set between $0.20 \mu \mathrm{m}$ and $4.0 \mu \mathrm{m}$, and the threshold values were set at 150 for SYBR-I and 300 for AO to permit cell recognition.

\section{Calculation of the lower detection limit}

The lower detection limit of the cells was calculated according to Kallmeyer et al., 2008. The probability $P$ of detecting one cell is given by the equation below:

$$
n=\frac{T_{\mathrm{fov}}}{C_{\mathrm{fov}}} \ln (1-p)
$$

where $C_{\text {fov }}$ represents fields of view on a filter with a total areas of $T_{\text {fov }}$ total fields of view, and $n$ is the number of cells required giving a probability $P$ of detecting a cell. The areas of the image fields were $5.7 \times 10^{-5} \mathrm{~cm}^{2}$ and $3.6 \times 10^{-4} \mathrm{~cm}^{2}$ for the $\times 100$ and $\times 40$ objectives, respectively. Given that the active filtration area of the polycarbonate membrane was $2.5 \mathrm{~cm}^{2}$, the total number of fields $T_{\text {fov }}$ became 43663 and 6986 for the $\times 100$ and $\times 40$ objectives, respectively; thus, 934 or 73 cells should be on the filter when the respective usual image numbers of 140 or 285 were applied. Converting of these numbers to the cell concentration in the original sediment, the lower detection limit would be $6.2 \times 10^{5}$ and $4.9 \times 10^{4}$ cells cm$^{-3}$ of the original sediments, when $1.5 \times 10^{-3} \mathrm{~cm}^{3}$ of sediment was applied to the filter.

\section{Cell recovery rate after centrifugation}

Although we usually filtered acid-wash sediment slurry without centrifugation, the centrifugation at $100 \mathrm{~g}$ may be sometimes required to remove major sediment particles and increase the volume of sediment that may be loaded onto the membrane. The recovery rate following these steps was evaluated by adding a known number of $E$. coli cells to heat-sterilized sediments (Core 2T-3, CK06-06) prepared as described earlier. The initial density of $E$. coli cells in the control slurry sample was 
$3.49 \pm 1.16 \times 10^{8}$ cells $\mathrm{cm}^{-3}$. Slurry was submitted to acid-wash treatment with $1 \% \mathrm{HF}$ for $20 \mathrm{~min}$ and the reaction was stopped by adding combinations of the following components: $1 \mathrm{M}$ Tris- $\mathrm{HCl}(\mathrm{pH}$ 8.0), $0.125 \mathrm{M}$ $\mathrm{CaCl}_{2}, 25 \%$ (v/v) methanol, $200 \mathrm{mM}$ sodium pyrophosphate, $0.5 \mathrm{M}$ EDTA, $0.2 \mathrm{M}$ sodium oxalate, $1 \%(\mathrm{w} / \mathrm{v})$ polyvinyl-polypyrrolidone (PVPP; Holben et al., 1988; Unge et al., 1999), 0.1\% (w/v) skim milk and $1 \times$ blocking solution (Roche, Basel, Switzerland). After sonication and centrifugation, the recovery rate of $E$. coli cells in each sample was determined by microscopic image analysis as described below. Even for the low centrifugation condition at $100 \mathrm{~g}$, coprecipitation of cells with sediment particles was found to be significant, whereas the effect of the acid washing on intracellular DNA integrity was minimal.

\section{Results and discussion}

Our method consists of the following independent steps: (1) cell detachment and silicate dissolution of sediments using $\mathrm{HF}$ and (2) fluorescent image calculation to exclude non-specific backgrounds. We constructed a computer-assisted automated microscope system that acquires multiple fluorescent images using different filters and then recognizes and counts fluorescent signals derived only from intracellular DNA by image analysis. This method provided high-quality, reproducible results with minimal fluctuation that were free of errors generated by human observation.

\section{Acid-wash treatment with $\mathrm{HF}$}

To enumerate the cell population in sediments, non-specific fluorescent signals, as well as autofluorescence from mineral particles must be eliminated as much as possible. On the image of the SYBR-I-stained filter, we found much non-autofluorescent, but SYBR-I-stainable particulate matter-so-called SYBR-SPAM (Figure 1)-in control sediments heat sterilized at $450{ }^{\circ} \mathrm{C}$ for $3 \mathrm{~h}$. As a potential background source, calcium carbonate in sediments is usually dissolved by acid washing (Figure 2a, Kallmeyer et al., 2008). However, HCl seemed almost totally ineffective against SYBRSPAM in marine sediments (Figure 2b). In contrast, $1 \%(\mathrm{v} / \mathrm{v}) \mathrm{HF}$ for $20 \mathrm{~min}$ at room temperature dissolved non-cellular sediment matrix like amorphous silica (Figure 2a), and significantly eliminated SYBR-SPAM and other extracellular biomolecules (Figure 2b). Nevertheless, 1\% HF treatment did not cause any deterioration of $E$. coli cells in terms of SYBR-I staining (Figure 3), indicating that intracellular DNA was minimally hydrolyzed under these conditions. We tested the acidwash treatment with several cultures and soil samples, which showed almost no or very little damage to intracellular DNA (data not shown). After the acid-wash reaction, $\mathrm{pH}$ of the slurry was

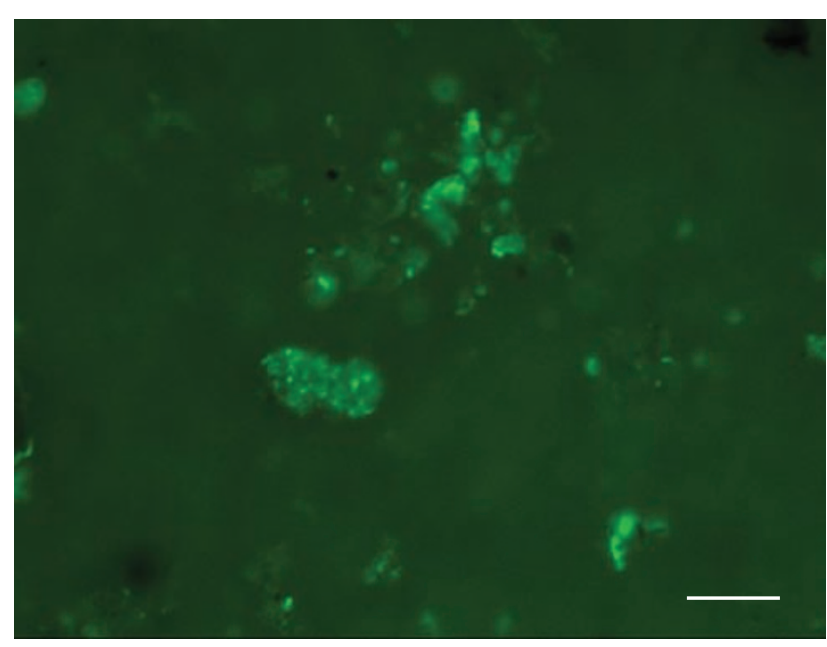

Figure 1 Typical image of SYBR Green I-stainable particulate matter (SYBR-SPAM) in microbe-free, heat-sterilized $\left(450^{\circ} \mathrm{C}\right.$ for $3 \mathrm{~h})$ sediment. Bar: $10 \mu \mathrm{m}$.
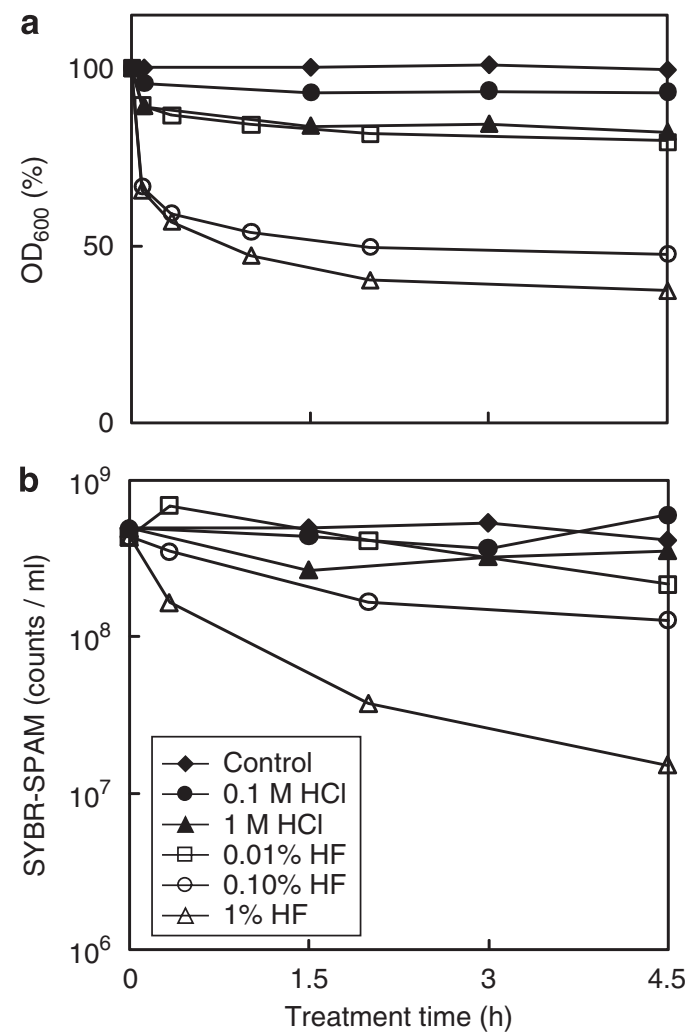

Figure 2 Effect of $\mathrm{HCl}$ and HF concentrations on SYBR-SPAM. $50 \mathrm{ml}$ of sediment slurry (Core 2T-3, CK06-06: 10\% in PBS buffer $(\mathrm{v} / \mathrm{v})$ ) was first gently centrifuged at $100 \mathrm{~g}$ for $4 \mathrm{~min}$ to remove heavy particles, and then the supernatant was mixed with 0.01 , 0.1 and $1 \mathrm{M} \mathrm{HCl}$ or $0.01,0.1$ or $1 \%(\mathrm{v} / \mathrm{v}) \mathrm{HF}$. (a) Time course of OD600 shown as relative \% against value before reaction started. (b) Number of SYBR-SPAM signals determined by computer enumeration without image analysis.

adjusted with Tris-HCl buffer (pH 8.0) and HF was precipitated with $\mathrm{CaCl}_{2}$ as CaF. Microscopic observation showed no auto-fluorescence from $\mathrm{CaF}$ particles. 

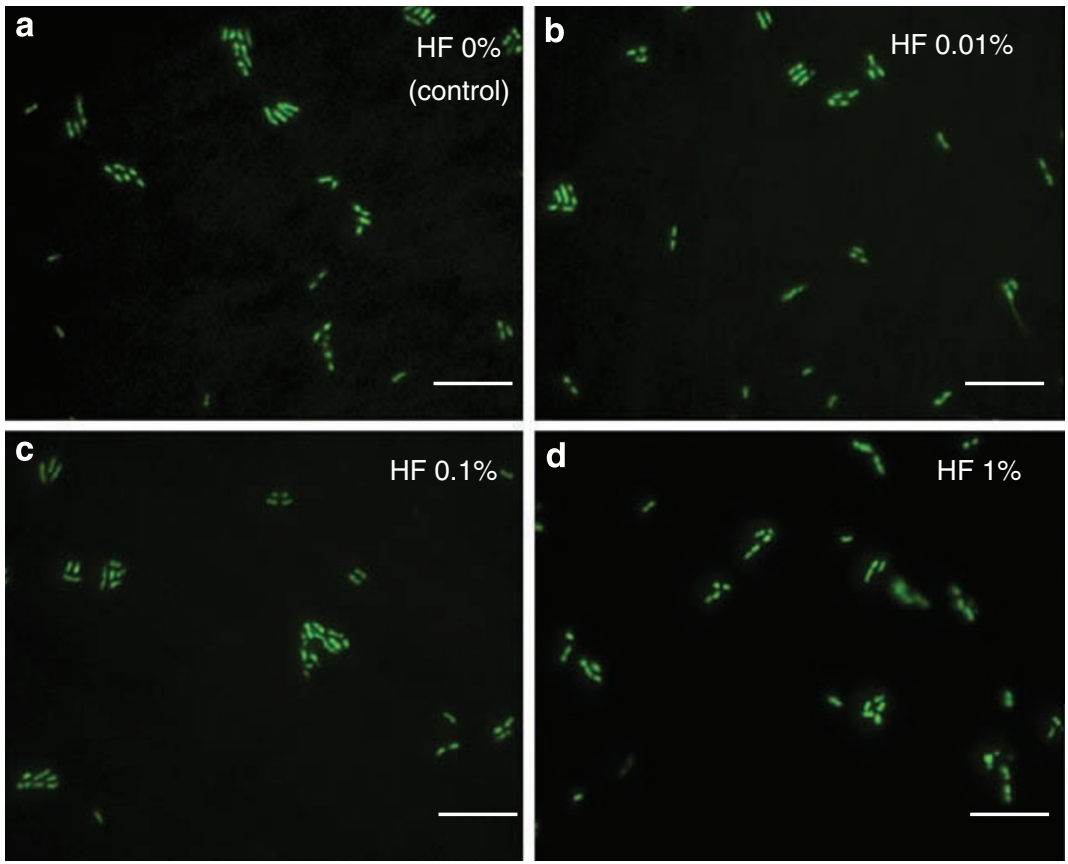

Figure 3 E. coli cells washed with HF. (a) $0 \%(\mathrm{w} / \mathrm{v}) \mathrm{HF}$, (b) $0.01 \% \mathrm{HF}$, (c) $0.1 \% \mathrm{HF}$ (d) $1 \% \mathrm{HF}$. All images of SYBR-I-stained E. coli cells were acquired after washing with $\mathrm{HF}$ for $20 \mathrm{~min}$ at room temperature. Bars: $10 \mu \mathrm{m}$.

Image analysis using automated microscope system Discriminative detection of cell-derived SYBR-I fluorescent signals in a forest of SYBR-SPAM required subsequent fluorescence calculations from image. We found that when SYBR-I bound to SYBRSPAM the SYBR-I spectra shift to longer wavelengths (Figure 4a), which can be distinguished from cell-derived green fluorescence when the fluorescent image is obtained with a long-pass filter of cutoff wavelength $510 \mathrm{~nm}$ (Figure $4 \mathrm{~b}$ ). The intensity of intracellular double stranded DNA is sharply enhanced without a significant change from the original spectrum (Sunamura et al., 2003). To discriminate the cell-derived fluorescent signal more precisely, we obtained microscopic images using band-pass filters at 528/38 and $617 / 73 \mathrm{~nm}$ (center wavelength/bandwidth) that separated the green and red components of SYBR-I fluorescence (Figures 5a, b, d and e). We divided the fluorescent intensity of green by that of the red images to obtain relative intensity profiles of green/red fluorescence in which cell-derived fluorescence was successfully discriminated as bright signals, whereas SYBRSPAM and other background signals were entirely eliminated (Figures 5c and f). We have tested SYBR Green II; however, it was found to be difficult to discriminate cell-derived fluorescence from nonspecific signals by the image analysis because SYBR-SPAM produce similar fluorescence spectra with cell-derived SYBR-II signals.

The computer-assisted microscope system automatically executed the commands to acquire fluorescent images and analyzed the images to discriminate fluorescent signals derived from cells. To adjust fine focus throughout the images independent of the fluorescent signals per microscopic field, we added microspheres that fluoresced only under UV excitation. Using MetaMorph version 7.5 software (Molecular Devices) with the original macros, the automated microscope system focused on under UV, and then switched the filter unit to capture the fluorescent images of 140 microscopic fields $(8.5 \mathrm{~s}$ per microscopic field, $20 \mathrm{~min}$ per sample; see Supplementary Figure 1), and carried out division and enumeration of the images ( $3 \mathrm{~s}$ per image, 7 to $8 \mathrm{~min}$ per sample). This device greatly reduced the time required for sample processing compared with direct manual cell counting and increased the number of examined microscopic fields statistically.

\section{Cell abundance in marine subsurface sediments}

We verified the utility of our method using more than 100 sub-seafloor sediment samples down to $365 \mathrm{~m}$ below the seafloor (mbsf). The computer count without image analysis seriously overestimated the biomass in all of the samples, even with AO staining, which had been widely used for manual cell counting in marine subsurface sediments (that is, AODC). The counts obtained from image-processed data, however, which were two to three orders of magnitude lower than those without image analysis, were within one order of magnitude to those counted by AODC with a professionally trained human eye (average difference; $-25 \%$ from 

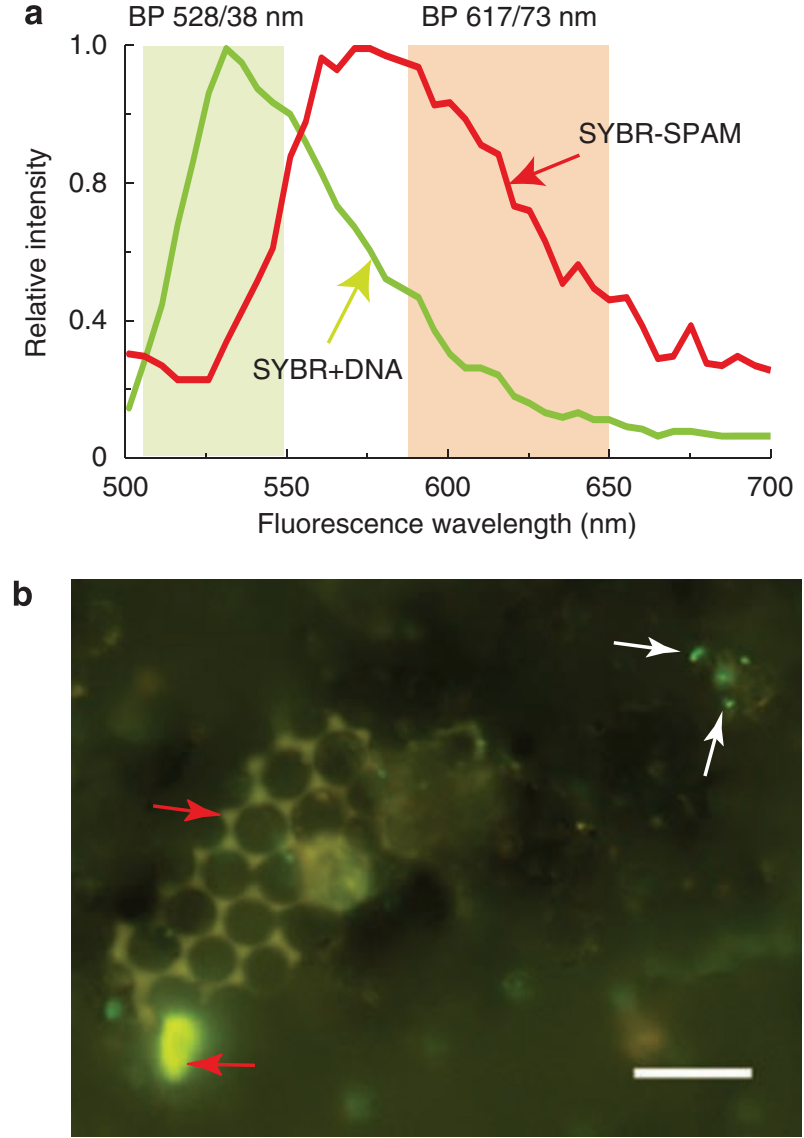

Figure 4 Difference of SYBR-I fluorescence spectrum between intracellular DNA and SYBR-SPAM. (a) Spectrum patterns show 'red shift' of SYBR-I fluorescence. When SYBR-I binds to SYBRSPAM, fluorescent spectra shift to longer wavelengths overall (red line), whereas fluorescent spectra of cell-derived SYBR-I (solid green line) do not shift at all or shift very little from the original SYBR-I spectrum (Sunamura et al., 2003). Green and orange shading areas show the wavelength range of 528/38, 617/73 (nm of center wavelength/bandwidth) band-pass filters, respectively. (b) Examples of fluorescence-producing cellular and non-cellular objects stained with SYBR-I. Red arrows denote yellowish SYBRSPAM and white arrows denote green E. coli cells. The image was obtained using a long-pass filter of cut-off wavelength $510 \mathrm{~nm}$. Bar: $10 \mu \mathrm{m}$.

image analysis data, $n=10$ : see Figure $6 a)$. These results indicate that SYBR-SPAM poses a serious problem in determining the population of microbial cells in environmental samples. Nevertheless, by image analysis as described here we were able to verify earlier AODC data from marine subsurface sediments off Peru.

Another finding of interest is that SYBR-SPAM became resistant to HF with increasing depth (Figure 6b), most likely due to the mineralogical alternation or compaction of amorphous silica during the burial. This indicates that an increased amount of SYBR-SPAM could seriously interfere with the detection and enumeration of microbial life in deep sub-seafloor sediments. In the two deepest samples at Site 1230 in Figure 6a, a slight overestimation of the cell number was observed in
AODC profile (average difference; $+91.6 \%$ from image analysis data, $n=2$ ), suggesting that discriminative counting of low biomass habitats close to the limits of Earth's biosphere is probably difficult even by a professionally trained human eye. To explore the very deep sub-seafloor biosphere by the future scientific ocean drilling, the method and microscopic device in this study will be useful.

\section{Detection limit}

The lower limit of detection comprises another important issue for accurate cell enumeration, especially for potentially low biomass habitat close to the limit of biosphere (Hoehler 2004; D'Hondt et al., 2007). We have usually applied up to $15 \mu \mathrm{l}$ of 1:10 sediment onto a filter and acquired 140 image fields using a $\times 100$ objective lens for cell counting. The theoretical lower limit under these conditions is $6.2 \times 10^{5}$ cells cm$^{-3}$ for detecting at least one cell with $95 \%$ probability (Kallmeyer et al., 2008). One of the options is to use $\times 40$ objective lens and observe a wider area. We preliminary counted E. coli cells using a $\times 40$ objective lens and increased the number of images to 285, which can lower the detection limit to $4.9 \times 10^{4}$ cells $\mathrm{cm}^{-3}$ without loss of the number of fluorescent signals, whereas maintaining the time required for total analysis to $1 \mathrm{~h}$. The image resolution of $\times 40$ objective lens in our microscope system is $161 \mathrm{~nm}$ pixcel $^{-1}$, which is enough for the detection of cell-derived fluorescent signals. The detection limit may also be lowered by increasing the volume of the sediment, which is currently equivalent to $1.5 \times 10^{-3} \mathrm{~cm}^{3}$ of sediment after washing with $\mathrm{HF}$ treatment. To prevent membrane clogging, brief centrifugation at $100 \mathrm{~g}$ (Lunau et al., 2005) or density gradient separation (Kallmeyer et al., 2008) that reduces mineral particles enables larger amounts of sediment to be placed on the filter, which extends the detection limit by $10-$ to 1000 -fold. However, we note that the recovery rate will depend on natural cell densities and field conditions. We have tested a variety of treatments to recover cells after the centrifugation (Figure 7). However, use of a centrifugation step should be carefully considered because of the relatively low recovery rate.

\section{Conclusion}

In this study, we showed that (1) the technique presented here is useful for quantitative studies of cell abundances in marine sediments; (2) objective, repeatable and hence reliable data can be obtained by automated image analyses; (3) earlier cell counts by AODC in marine sediments down to approximately $100 \mathrm{mbsf}$ and biogeochemical budgets based on these counts are now confirmed by an independent method. Hence, this method solves various problems with manual cell counts in natural 

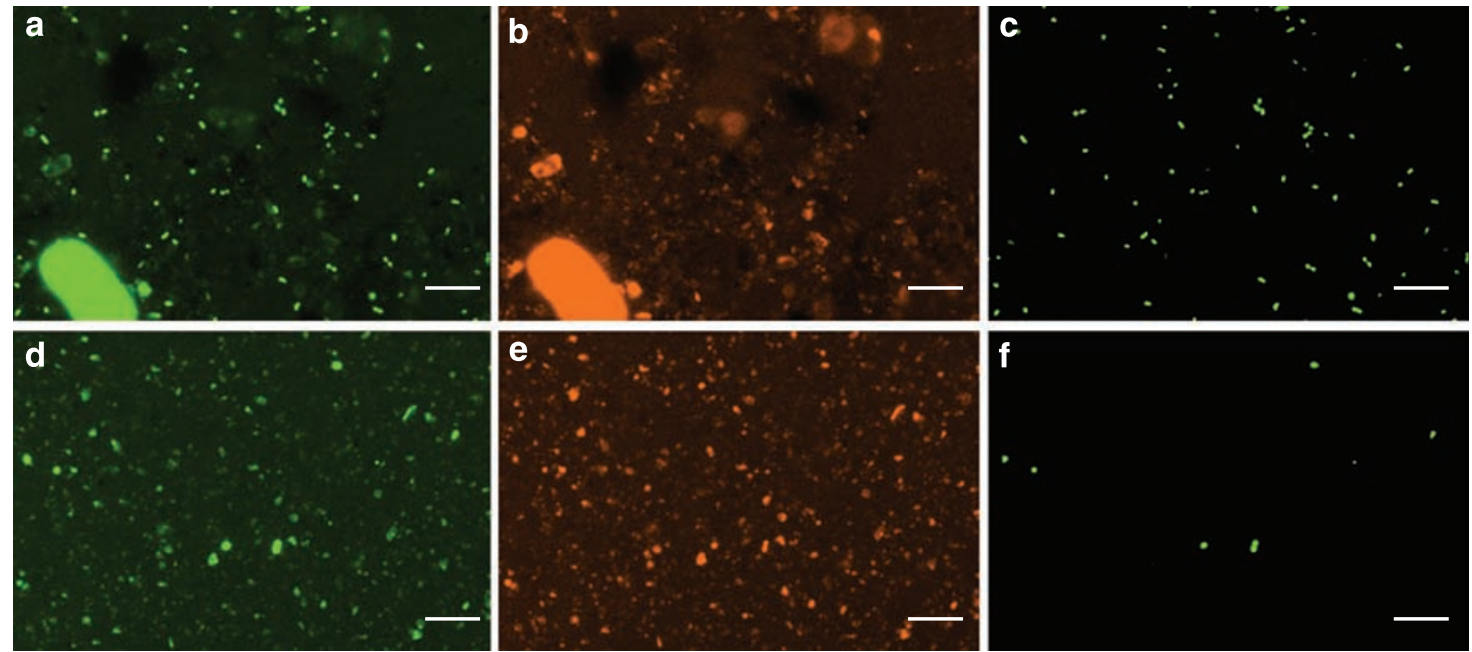

Figure 5 Discrimination of cell-derived SYBR Green I fluorescence from background signals using image analysis. Image analysis to distinguish cell-derived SYBR-I signals from SYBR-SPAM in heat-sterilized control sediments mixed with E. coli (a-c) and natural marine sediments (d-f: core 1H-1 of Site C0006 Hole E in the IODP Exp. 316). Fluorescent microscopic images taken using band-pass filters of 528/38 (a and $\mathbf{d}$ ) and 617/73 (b and e). Relative intensity profiles of green/red fluorescence (c and f) show only cell-derived fluorescent signals without background fluorescence. Bars: $10 \mu \mathrm{m}$.
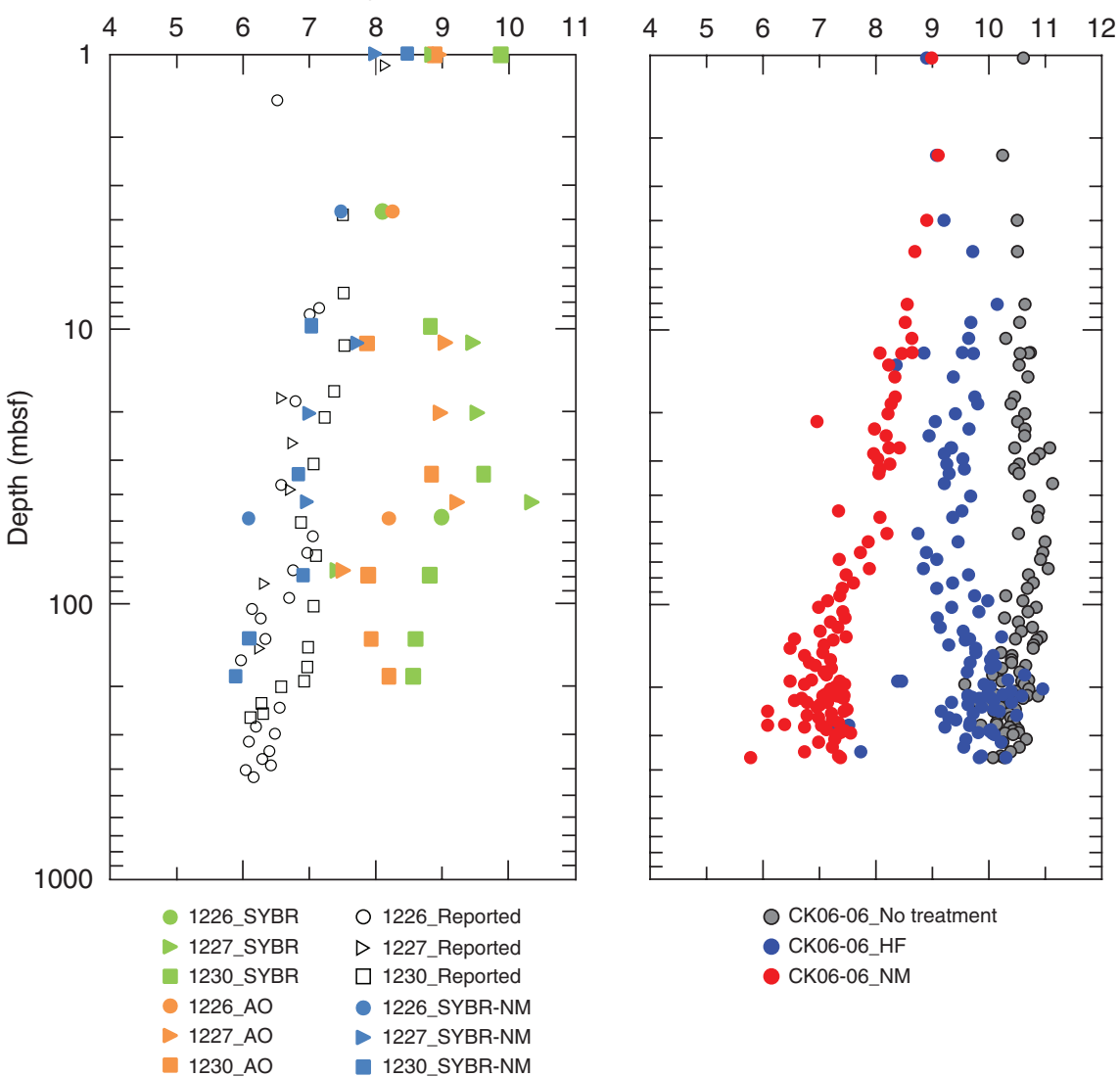

Figure 6 Comparison of microbial cell abundance in sub-seafloor sediments enumerated by various methods. (a) SYBR-I or AO counts in sediments collected by the ODP Leg 201 off Peru at Sites 1226 (circle), 1227 (triangle) and 1230 (square). Open plots: AODC with trained-eye recognition (D'Hondt et al., 2004). Green plots: SYBR-I-computer counts without image analysis. Orange plots: AO-computer counts without image analysis. Blue plots: SYBR-I-computer counts with new method (NM) using HF-wash and image analysis. Intensity thresholds for signal recognition were set at 150 and 300 for SYBR-I and AO counting without image analysis, respectively. Threshold for the image analysis was 110. (b) SYBR-I-computer counts of fluorescent signals in sediments off Japan collected by the Chikyu shakedown expedition CK06-06. Gray plots: no acid-wash and no image analysis. Blue plots: after HF-wash with no image analysis. Red plots: after $\mathrm{HF}$-wash with image analysis (NM). 


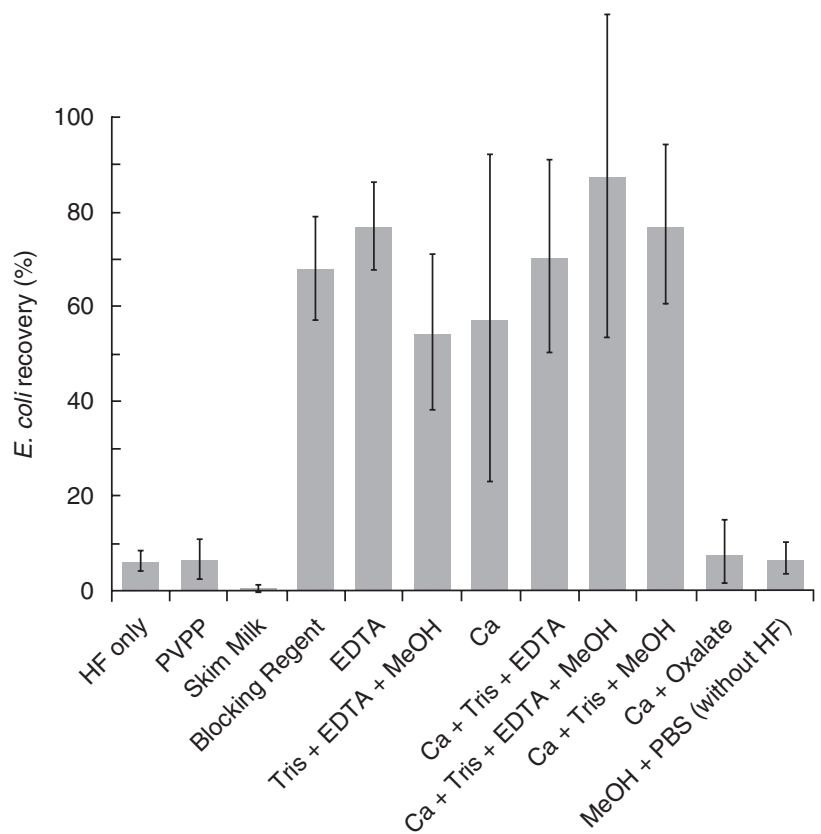

Figure 7 Effect of centrifugation $(100 \mathrm{~g})$ on the recovery rates of E. coli cells from marine sediments. After washing with $\mathrm{HF}$ and centrifugation, the reactions were stopped using various solutions. Error bars represent standard deviation in 140 images.

environments and should be widely used for cell enumeration in soils and sediments, especially in low biomass habitats of our planet or other celestial bodies.

\section{Acknowledgements}

We thank Ms Satoko Tanaka for sample filtration and microscope operation and Molecular Devices Japan and Olympus Co. for developing the software macros and the automated cell counting system. We are grateful to the shipboard scientists and crews of the ODP Leg 201, the Chikyu Shakedown Expedition CK06-06, and the IODP Expedition 316 for sampling and data. This study was supported in part by the JAMSTEC Multidisciplinary Research Promotion Award 2008 (to YM and FI).

\section{References}

Cragg BA, Parkes RJ, Fry JC, Weightman AJ, Maxwell JR, Kastner $\mathrm{M}$ et al. (1995). Bacterial profiles in deep sediments of the Santa Babara Basin, Site 893. Proc ODP Sci Res 146(Part 2): 139-144.

Daley RJ, Hobbie JE. (1975). Direct counts of aquatic bacteria by a modified epifluorescence technique. Limnol Oceanogr 20: 875-882.

D'Hondt S, Rutherford S, Spivack AJ. (2002). Metabolic activity of subsurface life in deep-sea sediments. Science 295: 2067-2070.

D’Hondt S, Jørgensen BB, Miller DJ, Batzke A, Blake R, Cragg BA et al. (2004). Distributions of microbial activities in deep subseafloor sediments. Science 306: 2216-2221.
D’Hondt S, Inagaki F, Ferdelman T, Jørgensen BB, Kato K, Kemp P et al. (2007). Exploring subseafloor life with the Integrated Ocean Drilling Program. Sci Drilling 5: 26-37.

Engelen B, Ziegelmüller K, Wolf L, Köpke B, Gittel A, Cypionka $\mathrm{H}$ et al. (2008). Fluids from the oceanic crust support microbial activities within the deep biosphere. Geomicrobiol J 25: 56-66.

Hoehler TM. (2004). Biological energy requirements as quantitative boundary conditions for life in the subsurface. Geobiology 2: 205-215.

Holben WE, Jansson JK, Chelm BK, Tiedje JM. (1988). DNA probe method for the detection of specific microorganisms in the soil bacterial community. Appl Environ Microbiol 54: 703-711.

Inagaki F, Suzuki M, Takai K, Oida H, Sakamoto T, Aoki K et al. (2003). Microbial communities associated with geological horizons in coastal subseafloor sediments from the Sea of Okhotsk. Appl Environ Microbiol 69: 7224-7235.

Inagaki F, Nunoura T, Nakagawa S, Teske A, Lever M, Lauer A et al. (2006). Biogeographical distribution and diversity of microbes in methane hydrate-bearing deep marine sediments on the Pacific Ocean Margin. Proc Natl Acad Sci USA 103: 2815-2820.

Inagaki F, Nakagawa S. (2008). Spatial distribution of the subseafloor life: diversity and biogeography. In Dilek Y, Furnes H, Muehlenbachs (eds). Links Between Geographical Processes, Microbial Activities \& Evolution of Life. Springer Science+Business Media B.V, 2008 pp 135-158.

Kallmeyer J, Smith DC, Spivack AJ, D’Hondt S. (2008). New cell extraction procedure applied to deep subsurface sediments. Limnol Oceanogr Methods 6: 236-245.

Kobayashi T, Koide O, Mori K, Shimamura S, Matsuura T, Miura T et al. (2008). Phylogenetic and enzymatic diversity of deep subseafloor aerobic microorganisms in organics- and methane-rich sediments off Shimokita Peninsula. Extremophiles 12: $519-527$.

Lipp JS, Morono Y, Inagaki F, Hinrichs K-U. (2008). Significant contribution of Archaea to extant biomass in marine subsurface sediments. Nature 454: 991-994.

Lunau M, Lemke A, Walther K, Martens-Habbena W, Simon M. (2005). An improved method for counting bacteria from sediments and turbid environments by epifluorescence microscopy. Environ Microbiol 7: 961-968.

Masui N, Morono Y, Inagaki F. (2008). Microbiological assessment of circulation mud fluids during the first operation of riser drilling by the deep-earth research vessel Chikyu. Geomicrobiol J 25: 274-282.

Noble RT, Fuhrman JA. (1998). Use of SYBR Green I for rapid epifluorescence counts of marine viruses and bacteria. Aquatic Microb Ecol 14: 113-118.

Parkes RJ, Cragg BA, Bale SJ, Getliff JM, Goodman K, Rochelle PA et al. (1994). Deep bacterial biosphere in Pacific Ocean sediments. Nature 371: 410-413.

Parkes RJ, Cragg BA, Wellsbury P. (2000). Recent studies on bacterial populations and processes in subseafloor sediments: A review. Hydrogeol J 8: 11-28.

Patel A, Noble RT, Steele JA, Schwalbach MS, Hewson I, Fuhman JA. (2007). Virus and prokaryote enumeration from planktonic aquatic environments by epifluorescence microscopy with SYBR Green I. Nature Protoc 2: 269-276. 
Poter KG, Feig YS. (1980). The use of DAPI for identifying and counting aquatic microflora. Limnol Oceanogr 25: 943-948.

Roussel EG, Bonavita MC, Querellou J, Cragg BA, Webster G, Prieur D et al. (2008). Extending the sub-sea-floor biosphere. Science 320: 1046.

Sunamura M, Maruyama A, Tsuji T, Kurane R. (2003). Spectral imaging detection and counting of microbial cells in marine sediment. J Microbiol Methods 53: 57-65.

Teske AP. (2006). Microbial communities of deep marine subsurface sediments: Molecular and cultivation surveys. Geomicrobiol J 23: 357-368.
Unge A, Tombolini R, Molbak L, Jansson JK. (1999). Simultaneous monitoring of cell number and metabolic activity of specific bacterial populations with a dual gfp-luxAB marker system. Appl Environ Microbiol. 65: 813-821.

Weinbauer MG, Beckmann C, Höfle MG. (1998). Utility of green fluorescent nucleic acid dyes and aluminum oxide membrane filters for rapid epifluorescence enumeration of soil and sediment bacteria. Appl Environ Microbiol 64: 5000-5003.

Whitman WB, Coleman DC, Wiebe WJ. (1998). Prokaryotes: The unseen majority. Proc Natl Acad Sci USA 95: 6578-6583.

Supplementary Information accompanies the paper on The ISME Journal website (http://www.nature.com/ismej) 